\title{
Experimental investigation and modelling of T-stubs undergoing large displacements
}

\author{
A.C. Faralli ${ }^{1}$, M. Latour ${ }^{2 *}$, P.J. $\operatorname{Tan}^{1}$, G. Rizzano ${ }^{2}$, P. Wrobel ${ }^{1}$ \\ ${ }^{1}$ Department of Mechanical Engineering, University College London, Torrington Place, \\ London WC1E 7JE, UK \\ ${ }^{2}$ Department of Civil Engineering, University of Salerno, Italy
}

\begin{abstract}
This paper investigates the development of second $\left(2^{\text {nd }}\right)$ order effects, arising from geometric and material non-linearities of T-stubs bolted to a rigid support, through a combination of experimental, numerical and analytical approaches. Experimental data is presented for a broad range of T-stub geometries, designed to ensure that significant $2^{\text {nd }}$ order effects always develop, that will complement the existing library of limited test results. Finite element models, incorporating combined tensile (ductile) and shear damage initiation, evolution and failure in both the flange and bolt, are also developed to elucidate how key geometric/material parameters influence the resistance and ductility of T-stubs undergoing large displacement. It will be shown that the restraining effect from the bolt is integral to the activation of catenary action in the flange and the development of a second hardening branch in the tensile response, leading to identification of two new modes of failure that are not currently considered in classical theory or by EC3 (Part 1.8). A mechanical model is formulated to identify the key geometric and material parameters controlling the initiation, and development, of the second hardening branch. Finally, a criterion is proposed to estimate the critical displacement from when $2^{\text {nd }}$ order effects become active.
\end{abstract}

Keywords: T-stub, robustness, large displacements, second-order effects, shear, membrane

\footnotetext{
${ }^{*}$ Corresponding author (M. Latour).

Email address: pj.tan@ucl.ac.uk (P.J. $\operatorname{Tan}^{1}$ ) ; mlatour@unisa.it (M. Latour ${ }^{2}$ )
} 


\section{Introduction}

The robustness of Moment Resisting steel Frames (MRFs) is typically assessed by evaluating the response of structural members, and their connections, to large rotations [1 6 ]. A structural joint is one of the most vulnerable constituent of a MRF when subjected to exceptional loadings

5 - this has not been satisfactorily addressed in EC3 Part 1.8 [7]. When designing connections, spare deformation capacity would need to be built into the system to ensure smooth load transmission between connecting beams and columns. This is especially pertinent when catenary effects develop in the beams during which structural joints are subjected to significant axial stretch in addition to rotations. The need to accommodate large global displacement induces significant geometric and material non-linearities - giving rise to $2^{\text {nd }}$ order effects that cannot be ignored when characterising the rotational capacity of bolted joints. The rotational capacity of a beam-to-column joint is inextricably linked to the deformation capacity of its constituent components, such as the end-plate, the bolts or the column web panel zone 8 14. Mechanical models already exist that could predict, to a reasonable degree of accuracy, the global response of a structural joint using a component approach. However, they are contingent upon the accurate modelling/characterisation of the sources of stiffness, resistance and ductility in each component [7]. While substantial progress had already been made to characterise the mechanical response of the main joint components, most of these have focused on the modelling of the joint response where their rotations are suitable only for the development of first-order plastic analyses for frame design, such as those required for the design/check of MRFs in seismic zone. The influence of $2^{\text {nd }}$ order effects on the response of joint components undergoing large rotations [15-19] is still not yet well understood. As part of a wider program to address the aforementioned, the large displacement response of bolted T-stubs, one of the main components of a beam-to-column joint, will be investigated in this paper.

25

Experiments are often performed on coupled T-stubs comprising of two T-elements bolted together through their flanges. Piluso et al. 20] investigated the effects of material non-linearity for T-stubs of $m / d_{b} \approx 3$ and $m / t_{f} \approx 3$, where $m$ is the distance between the plastic hinge located at the web-to-flange attachment and the bolt line, and $d_{b}$ and $t_{f}$ are the nominal bolt diameter and flange thickness, respectively. A mechanical model [21] was developed that was shown to predict well the experimental load-displacement $(\mathrm{F}-\Delta)$ response even though it neglects geometric non-linearity. The influence of $m, t_{f}$ and $d_{b}$ on the resistance and deformation of 
T-stubs connected by thread-fixed one-side bolts were studied by Liu et al. 222 and Zhang et al. 23. Similar experiments were also performed by Girão Coelho [24 26] and Dinu et al. 27. although they were mainly for specimens with small $m / d_{b}$ and $m / t_{f}$ values.

The failure mode reported in the aforementioned typically involves a combination of tension and bending of the bolts. As yet, there is limited experimental data, apart from one reported by Latour and Rizzano 28, for T-stub dimensions of $m / d_{b} \geq 4$ and $m / t_{f} \geq 8$. They reported a second hardening branch $(2 \mathrm{HB})$ in the large displacement régime $\left(\Delta>4 t_{f}\right)$ - a consequence of the development of axial (membrane) stresses in the flange - where geometric non-linearity becomes significant. The same test was also repeated for one connected to a rigid support during which an even more pronounced hardening branch was observed to develop from a smaller global displacement of $\Delta>2 t_{f}$. A new failure mechanism was identified in the form of combined membrane action in the flange and shear stresses in the bolts. Zhao et al. 29] also reported on the development of a $2 \mathrm{HB}$ for their T-stubs (bolted to a rigid support ) of $m / d_{b}=5$ and $m / t_{f} \in\{7,10,15\}$. They found that the T-stubs failed as a result of membrane actions in the flange since the bolt diameter $(24 \mathrm{~mm})$ was much greater than $t_{f}$. Notwithstanding, it is unclear from the tests reported by Latour and Rizzano 28, and Zhao et al. 29, how different geometric combinations of $m / d_{b}$ and $m / t_{f}$ influence the mode of failure. Even though, collectively, the aforementioned provided some insights into the effects of material and geometric nonlinearities on the global response of T-stubs, little is yet known of how the dimensions of a T-stub affect the development of $2^{\text {nd }}$ order effects [28, 29. In addition, no mechanical model currently exists that could account for the influence of geometric non-linearity [20, 24, 27].

In this paper, we will examine how different T-stub (bolted to a rigid support) dimensions influence the development of $2^{n d}$ order effects (in their F- $\Delta$ response) through a combination of experimental, numerical and analytical approaches. T-stub geometries are carefully selected to ensure that second order effects always develop and is significant throughout. Different combinations of $m / d_{b}$ and $m / t_{f}$ are investigated to extend the range of the experimental studies highlighted previously. The effects of shear and membrane forces in the bolts and flange, respectively, are investigated and digital image correlation (DIC) will be employed to map the strain field evolution in the flange - the latter is used to validate the FE predictions. Finite element models, incorporating damage initiation and evolution, and the eventual failure of both the flange and bolt materials, are developed for the T-stubs. A simplified criterion is proposed to predict the onset of $2^{\text {nd }}$ order effects that originate from the contact between the bolt shaft and the bolt hole. Despite its simplicity, it will be shown, through comparison with experimental data and 
FE predictions, that the proposed criterion successfully identifies the key geometric and material parameters that influence the development of a second hardening branch (2HB).

\section{Methodology}

In this study, finite-element (FE) simulations and experiments were performed to elucidate how different T-stub geometries - conducted for T-stubs bolted to a rigid support - influence the development of $2^{n d}$ order effects in their corresponding F- $\Delta$ response. Their geometric dimensions were carefully chosen, in accordance to a preliminary study by Faralli et al. 30, to ensure that significant second order effects develop in all cases. Special considerations were given to cover the full range of the key geometric parameters to extend the results of existing experimental data [20, 24, 27,29] - this is achieved by selecting different combinations of $m / d_{b}$ and $m / t_{f}$ ratios. Each specimen is annotated as Mx-y-z where $\mathrm{x}, \mathrm{y}$ and $\mathrm{z}$ denote the values of $d_{b}, m / d_{b}$ and $t_{f}$, respectively. Three plate thicknesses (viz.,10,15 and $20 \mathrm{~mm}$ ) and three different bolt diameters (M16, M18 and M20) were used; hence, the $m / d_{b}$ ratio varies between a range of 3-5. Table 1 lists the geometric parameters of the T-stubs considered in this study. Based on the criterion

so in EC3 Part 1.8 [7], the selected T-stubs will develop either a Type-1 (plate fracture) or Type-2 (plate fracture in combination with bolt failure in tension) failure mechanism. 

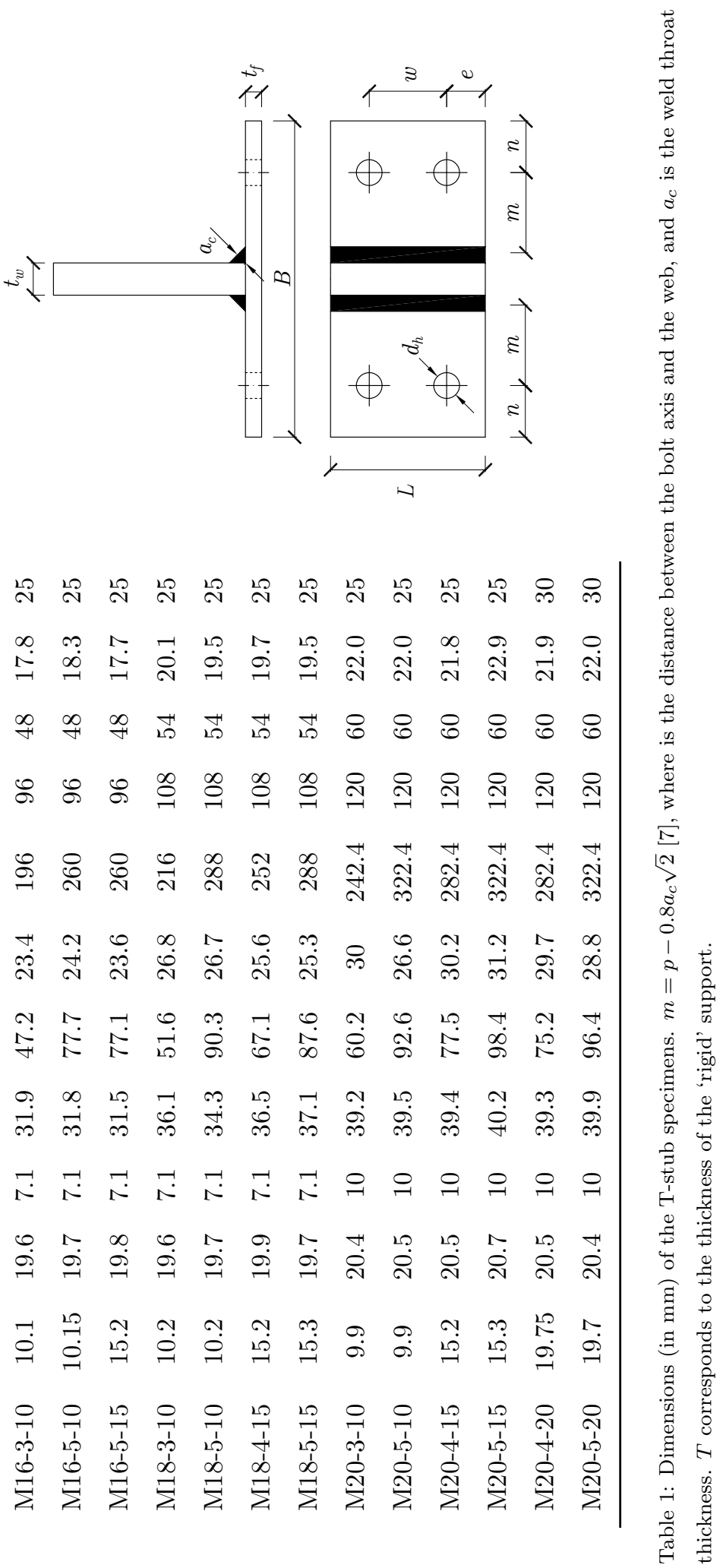


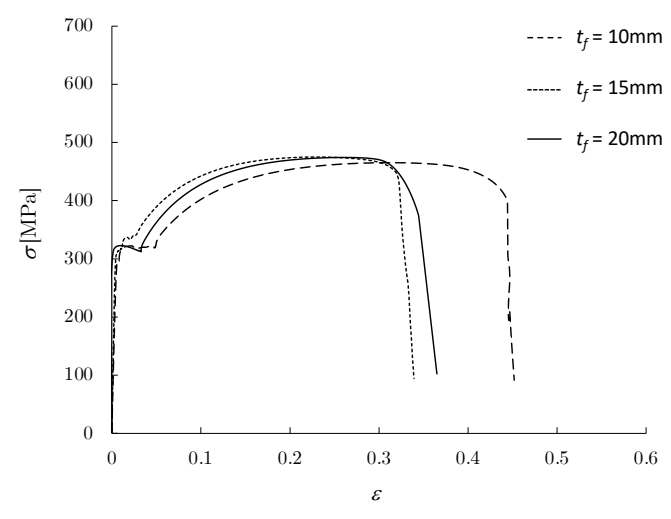

(a)

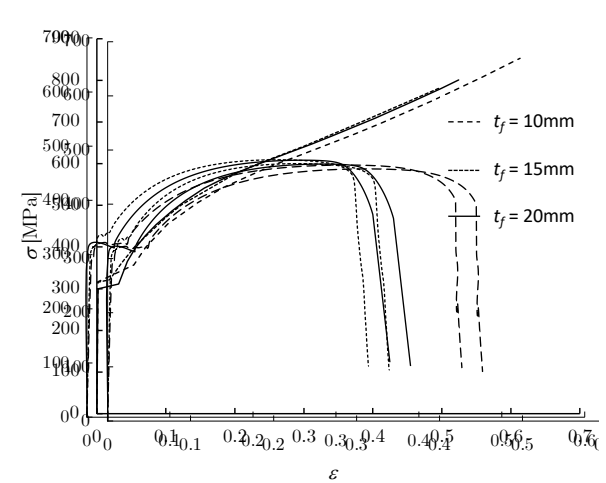

(b)

Fig. 1: (a) Nominal and (b) true plastic stress-strain curves for the S275 steel material, where $t_{f}$ is the plate thickness.

\subsection{Experiments}

\subsubsection{Material properties}

Material characterisation of the S275 steel plates, used to construct the flange, is performed using tensile coupon tests of different thickness. Figure 1 shows the results (nominal and true stress-strain curves) for the three plate thicknesses used in the experiments. The materials tested showed a scatter in the necking strain - this is due to statistical variation of the mechanical properties. The tensile F - $\Delta$ response of the Grade 10.9 bolts are given in Fig 22 . All three diameters, viz. M16, M18 and M20, showed a ductile tensile response with failure occurring at nominal strains in excess of $6 \%$ - they failed by necking localisation of the bolt shank as shown in Fig 3 . A special test assembly was designed/manufactured to characterise the shear resistance of the bolts and this was reported in Faralli et al. 31]; only their results are shown in Figs $2 p$ and 3 b.

\subsubsection{Tensile testing of bolted T-stubs}

Tensile testing were performed under displacement control, at a rate of $0.05 \mathrm{~mm} / \mathrm{s}$, using a Shenck Hydropuls Universal Testing machine (Load Capacity +/- $600 \mathrm{kN}$, Stroke $250 \mathrm{~mm}$ ), where the overall deformation is monitored through the machine load cell and displacement transducer. An axial load is applied to the web, which was clamped to the testing machine, as shown in Fig $4(a)$.

Digital image correlation (DIC), see Fig 4 , was also employed for the full-field strain mapping 


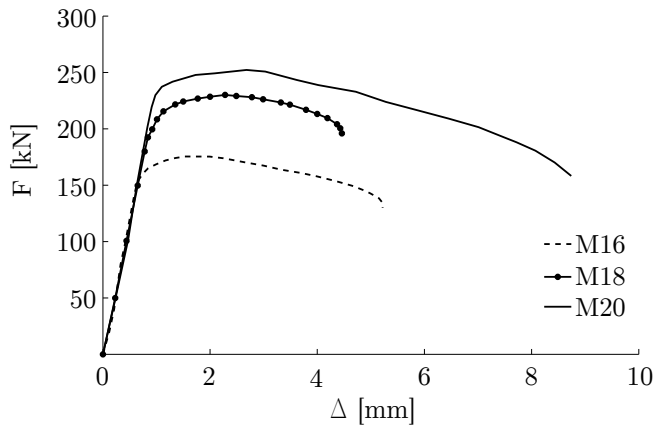

(a) Tensile tests.

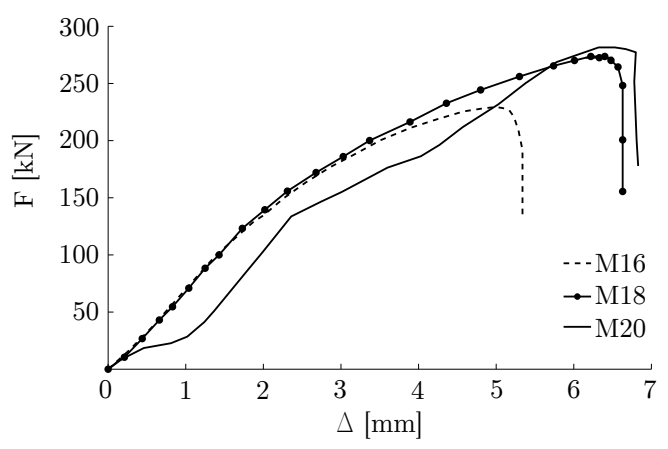

(b) Shear tests.

Fig. 2: Tensile and shear tests for three different bolt diameters.

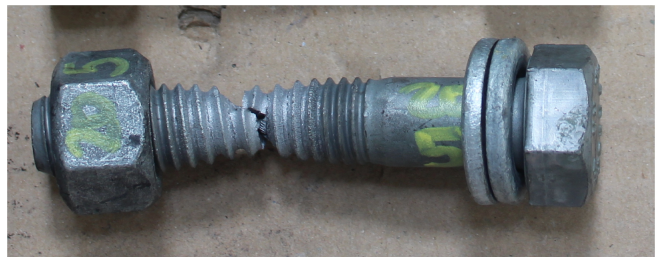

(a) Tensile failure

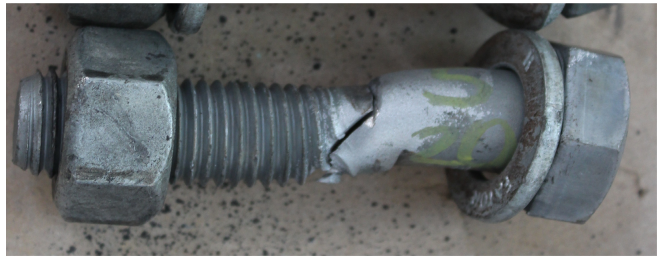

(b) Shear failure

Fig. 3: The deformed bolts at failure. 
in the plane of the specimen thickness. A correlation function $C$ was used to locate a reference

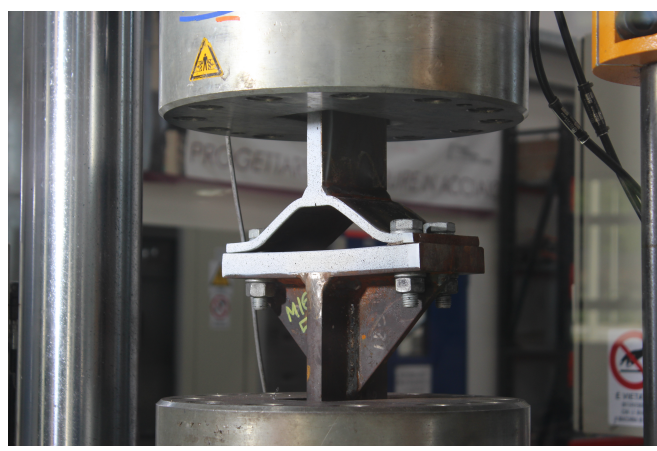

(a) Setup for tensile testing

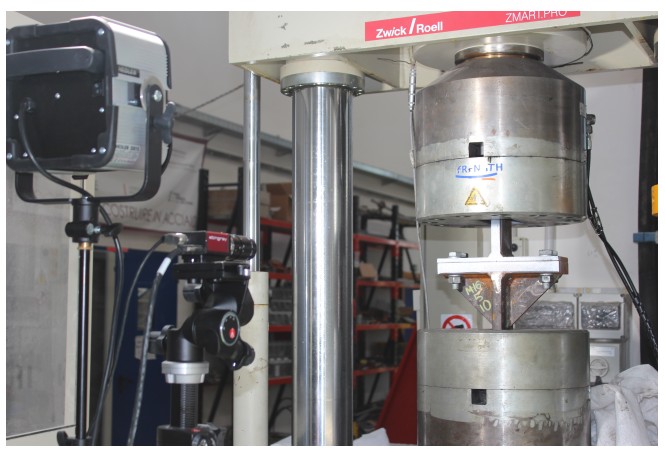

(b) Setup for the full-field strain mapping using DIC

Fig. 4: Experimental setup for the monotonic tensile testing of the T-stubs.

subset of pixels, given by

$$
C(x, y, u, v)=\sum_{i, j=-n / 2}^{n / 2}\left[I(x+i, y+j)-I^{*}(x+u+i, y+v+j)\right]^{2}
$$

where $(x, y)$ and $(u, v)$ are the original coordinates and the displacement of the pixel, respectively; $n$ is the size of the subset; $I$ and $I^{*}$ are the light intensities distribution reflected by the pixel before and after the deformation, respectively, and they correspond to a grade between 0 (no light intensity) and 255 (maximum light intensity). When the displacements $u$ and $v$ were obtained, the Green-Lagrangian strains are calculated as follows:

$$
\begin{aligned}
& \varepsilon_{x}=\frac{1}{2}\left[2 \frac{\partial u}{\partial x}+\left(\frac{\partial u}{\partial x}\right)^{2}+\left(\frac{\partial v}{\partial x}\right)^{2}\right] \\
& \varepsilon_{y}=\frac{1}{2}\left[2 \frac{\partial v}{\partial y}+\left(\frac{\partial u}{\partial y}\right)^{2}+\left(\frac{\partial v}{\partial y}\right)^{2}\right],
\end{aligned}
$$

where $\varepsilon_{x}$ and $\varepsilon_{y}$ are the in-plane principal strains. They are to be used later for comparison against finite element (FE) model predictions.

\subsubsection{Experimental results}

Figure 6 shows the experimental $\mathrm{F}-\Delta$ curves of the T-stub specimens and, as expected, they all failed in either a Type-1 or -2 failure mechanism. In every case, there is a significant influence by the bolts on the development of a second hardening branch (2HB). A $2 \mathrm{HB}$ - typically 


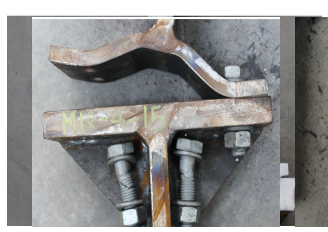

(a) M16-3-10

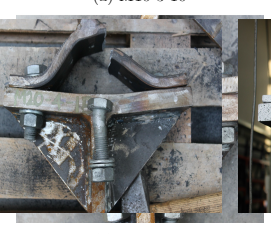

(e) M18-4-15

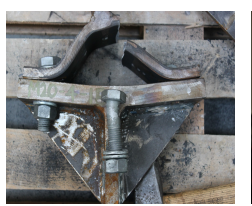

(i) $\mathrm{M} 20-4-15$

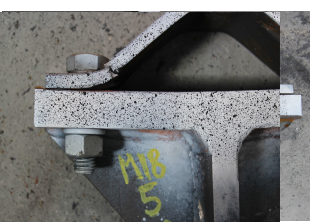

(b) M16-5-10

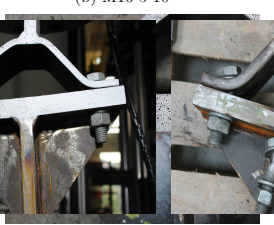

(f) M18-5-10

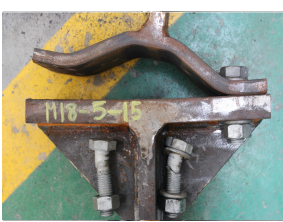

(c) M16-5-15

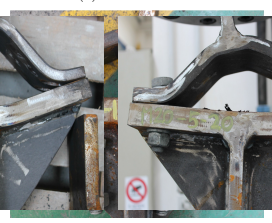

(g) M18-5-15

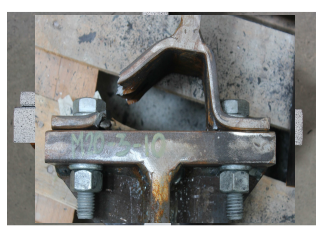

(d) M18-3-10

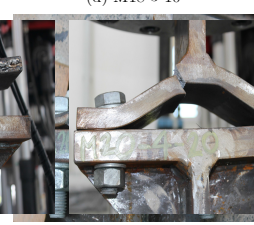

(h) M20-3-10

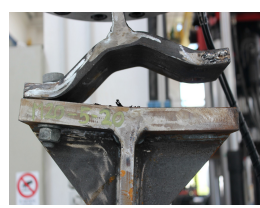

(1) M20-5-20

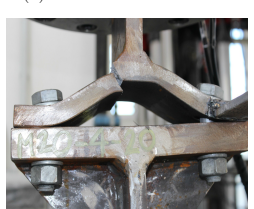

(m) $\mathrm{M} 20-4-20$

Fig. 5: Post-test (failed) specimens - see Table 2 for the classification of their failure mode.

observed for displacements between $15 \mathrm{~mm}$ to $30 \mathrm{~mm}$ - develops whenever the bolt shank comes into contact with the side wall of their respective bolt hole in the flange plate, leading to an abrupt rise in the overall T-stub stiffness. This increase in stiffness arises from the development of catenary action in the flange plate, activated through the restraining action from the bolts. During the second hardening branch of the $\mathrm{F}-\Delta$ curve, the bolt shank is subjected to significant shearing forces (in addition to bending and tension), caused by the relative horizontal displacement between the flange and the underlying rigid plate. Whenever a $2 \mathrm{HB}$ develops in a $\mathrm{F}-\Delta$ curve, failure occurs through one of the following mechanism/mode: (I) Weld-toe failure (failure of the flange plate at the flange-to-web attachment); (II) Necking of the bolt-hole (failure of the flange plate at the bolt line); or (III) Bolt failure under the combined actions of shear, tension and bending. Figure 5 shows the post-test specimens and they are categorised according to the aforementioned failure modes in Table 2 Note that Modes II and III are not currently considered in EC3 (Part 1.8), which was developed within the constitutive framework of limit analysis (rigid-plastic materials) where shear force in the bolts is neglected. It must be emphasised that the bolts are subjected to bending, shear and tensile forces; consequently, their failure is due to these combined actions.

Figure 6 reveals that nearly all the test specimens develop a distinct second hardening branch (2HB) when $\Delta \geq 15 \mathrm{~mm}$. This confirms that the study by Faralli et al. [30] correctly provides the 


\begin{tabular}{rlllll}
\hline Weld toe failure (Mode I): & M16-3-10 & M18-3-10 & M20-4-15 & M20-4-20 & M20-5-15 \\
\hline Necking of the bolt hole (Mode II) : & M16-5-10 & M18-5-10 & M20-3-10 & M20-5-10 \\
\hline Bolt failure (Mode III): & M16-5-15 & M18-4-15 & M18-5-15 & M20-5-20 \\
\hline
\end{tabular}

Table 2: Failure mode classification for the test specimens.

T-stubs sizing needed by them to develop a $2 \mathrm{HB}$. Only the M20-4-20 specimen exhibits a slightly different trend - it resembles those obtained in previous studies where geometric non-linearities were disregarded [21, 24, 27] - which can be attributed to a combination of the thick flange and a small $m / d_{b}$ ratio.

In the main, the $\mathrm{F}-\Delta$ response of a T-stub is influenced by two non-dimensional geometric parameters, viz. $m / d_{b}$ and $m / t_{f}$. Specimens with high $m / d_{b}$ and $m / t_{f}$ tend to exhibit a distinct 2HB (see, for example, M20-5-10) and have greater ductility: they are characterised by ultimate displacement of $\Delta_{u} \geq 5 t_{f}$, with the M20-5-15 specimen reaching $\Delta_{u}=7 t_{f} \approx 110 \mathrm{~mm}$. Their ultimate displacement appears unaffected by a decrease in $m / t_{f}$ so long as $m / d_{b} \geq 4$; however, the transition to a $2 \mathrm{HB}$ is somewhat less discernible, as exemplified by the M16-5-15 and M205-20 specimens. A further decrease in $m / t_{f}$, along with a decrease in $m / d_{b}$, leads to a $\mathrm{F}-\Delta$ response which is broadly similar to those reported in [20, 24, 27] with a significantly reduced ductility; $\Delta_{u}=2 t_{f}$ of the M20-4-20 specimen was the lowest recorded in this study. An exception to the above is the M18-4-15 specimen which appeared to develop a well-defined 2HB. Unlike T-stubs with small $m / d_{b}$ and $m / t_{f}$ values (viz. M16-3-10, M18-3-10, M20-4-15 and M20-4-20) where failure is a consequence of the membrane action that develops in the flange, the M18-4-15 specimen failed by fracture of its bolts through the combined action of tension and shear as shown in Fig. 5e. As noted by Latour and Rizzano 28, the development of shear stresses in the bolts should also be considered as a form of geometric non-linearity. Therefore, bolt fracture (as shown in Fig 7 a) should be regarded as another mode of failure. Specimens that fail due to shearing action in the bolts are generally characterised by $m / d_{b} \geq 5$ and $m / t_{f}=5$. By contrast, T-stubs with small $m / d_{b}$ and $m / t_{f}$ usually fail by through-thickness fracture at the weld toe (Fig 7b). This is consistent with Zhao et al. [29] where specimens with smaller $m / t_{f}$ value were observed to fail at the weld toe. Increasing $m / t_{f}$ leads to net-section plastic collapse as shown in Fig 7f: this involves necking of the flange at the bolt line, giving rise to a more ductile overall response compared to the one at the weld toe. 
In general, increasing the plate thickness or the bolt diameter, or their combination thereof, would lead to increased overall tensile resistance of a T-stub. Its ductility supply, however, can only be extended by increasing $m / d_{b}$ (Fig 6). The development of a $2 \mathrm{HB}$ in all the T-stubs (as listed in Table 2) always involved the participation of the bolt in shear. This leads to an ultimate resistance that is far beyond the expected value predicted by EC3 (Part 1.8) because geometric non-linearity is not considered. It is worth re-emphasising that geometric nonlinearity gives rise to a load resisting mechanism which is completely different from that considered by existing Eurocodes.

\subsection{Finite element modelling}

Three-dimensional FE models are developed for the T-stub specimens subjected to quasistatic tension using ABAQUS/Standard V6.13. C3D8R elements were used for the mesh and only a quarter of the T-stub is modelled owing to symmetry, see Fig 8 . The threaded region of each bolt is modelled as a cylinder with a cross-sectional area equivalent to the tensile stress area of $A_{s}$, whereas the nominal cross-sectional area is used for its unthreaded counterpart. Given the similarities between the true stress-strain curves (see Fig 1 1 ) obtained for different $t_{f}$, the data corresponding to $t_{f}=15 \mathrm{~mm}$ is used in the FE model since it is representative of all the specimens that were tested. The true stress-strain curve for the Grade 10.9 bolts that was used in the FE models are shown in Fig 9. The damage responses of both flange and bolt were modelled, and calibrated, following Faralli et al. 31]; details of their damage initiation and evolution are listed in Tables 3 to 5 .

\subsubsection{Comparison between experimental and numerical results}

Figure 6 shows good agreement between FE predictions and their experimental counterpart. In nearly all cases, the FE model accurately predicts the key response parameters, viz. stiffness, plastic and ultimate strength and ductility of the T-stubs. Notwithstanding, discrepancies exist. For instance, a loss of resistance is observed in the M20-3-10 specimen (see Fig 6 ). This is caused by self-adjustment of the bolt within the bolt-hole during the experiment, which is not captured by the FE model, and this explains the higher predicted resistance. In some instances, the deformation of the rigid support has affected the response of the T-stub, leading to a slight overestimation of the ultimate displacement, such as for the M20-5-10 specimen as shown in Fig 6 .

In general, the FE model is able to predict the characteristic shape of the experimental $\mathrm{F}$ - $\Delta$ response for a broad range of T-stub dimensions. Figures 10 and 11 compare the normal strain 


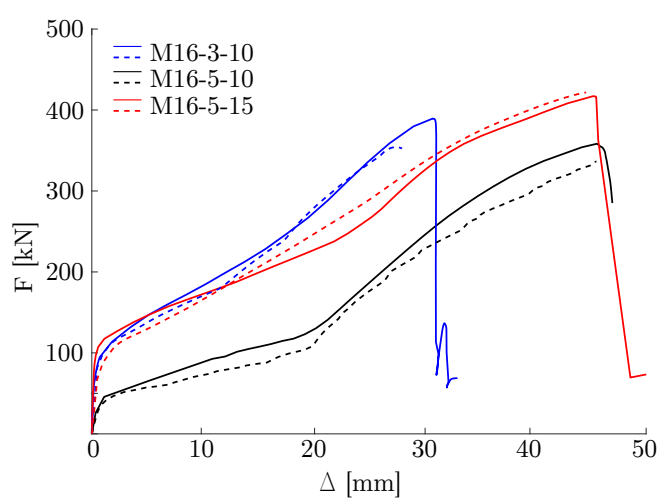

(a) M16 specimens

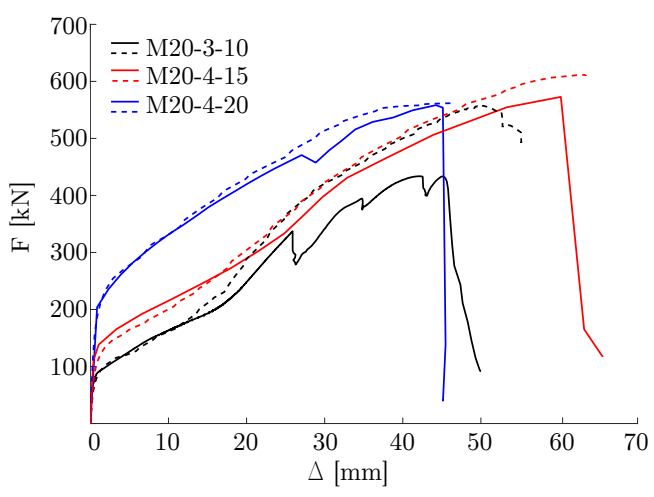

(c) M20 specimens - Set 1

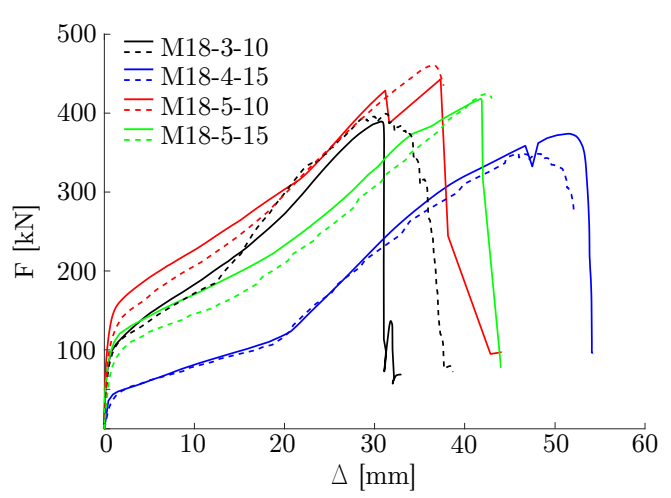

(b) M18 specimens

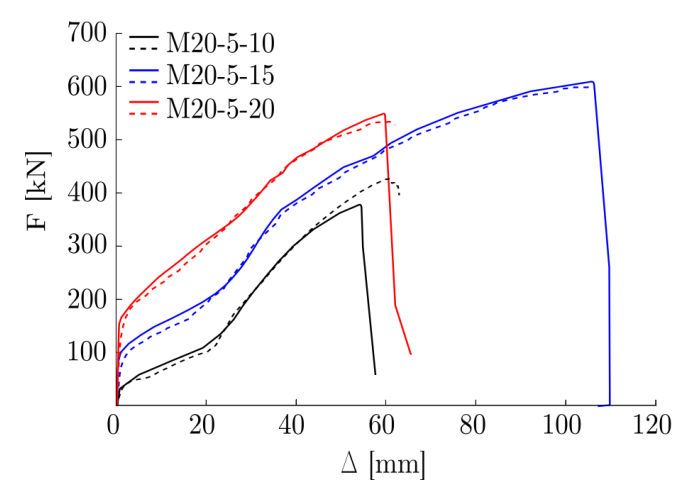

(d) M20 specimens - Set 2

Fig. 6: Comparison between experimental (solid) and numerical (dotted) F- $\Delta$ curves. 


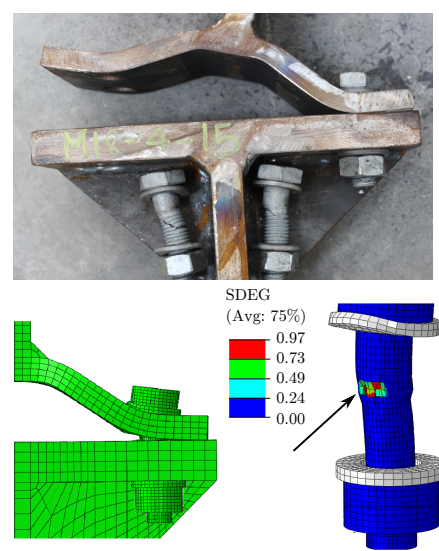

(a)

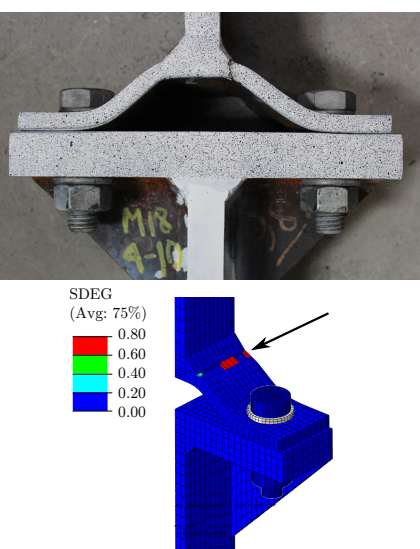

(b)

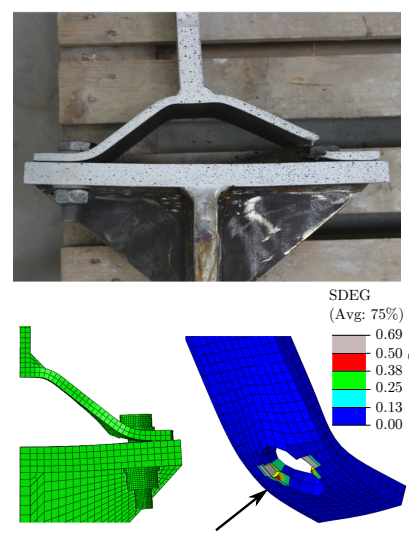

(c)

Fig. 7: Comparison between FE predictions and observed failure modes: (a) failure of bolt under shear (Specimen M18-4-15); (b) fracture of the flange at the weld-toe (Specimen M18-3-10); (c) fracture of the flange at the bolt line (Specimen M18-5-10). Arrows indicate deleted elements in the FE model and SDEG represents the scalar stiffness degradation variable.

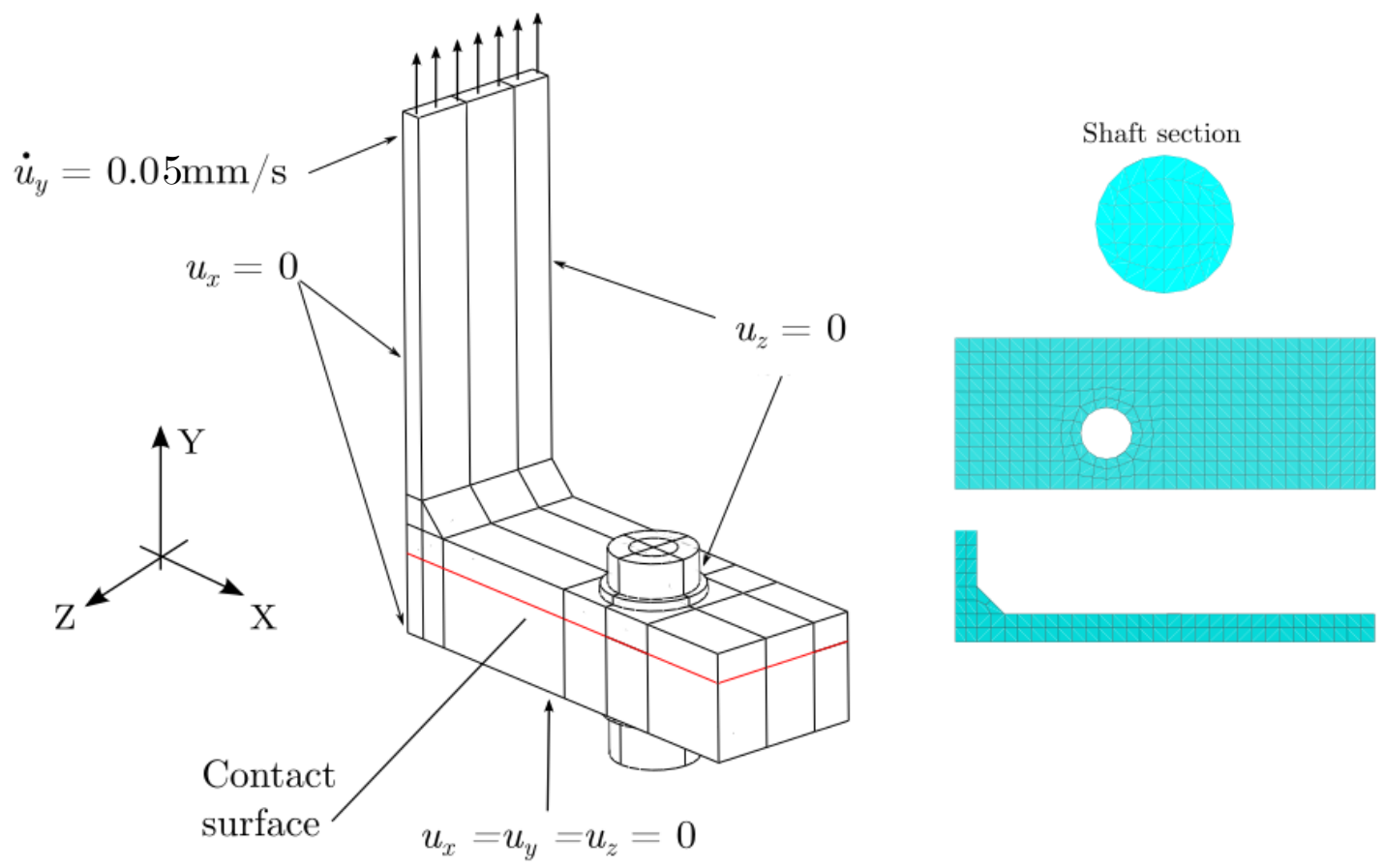

Fig. 8: Three-dimensional FE model of a T-stub specimen. The imposed displacement boundary conditions are as shown. 


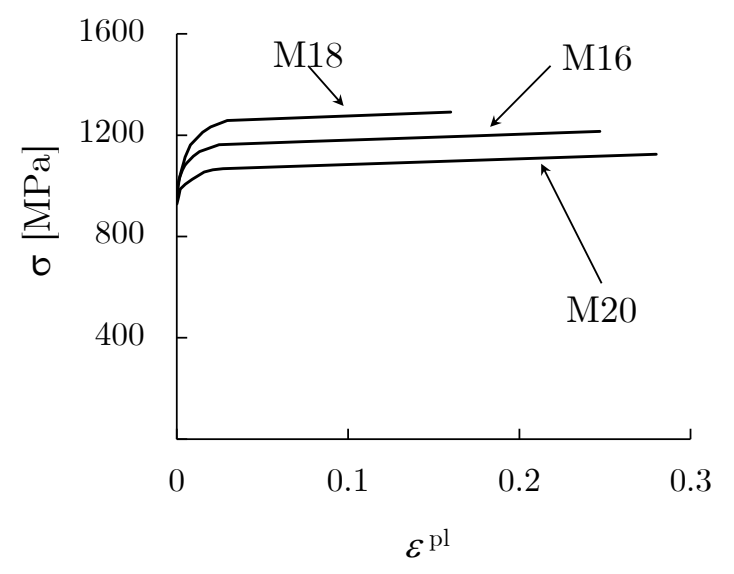

Fig. 9: True plastic stress-strain curves for the M16, M18 and M20 bolts.

Table 3: Damage initiation criteria for the S275 steel and 10.9 bolt grade.

\begin{tabular}{ccccc} 
& $\mathrm{S} 275$ & $\mathrm{M} 16$ & $\mathrm{M} 18$ & $\mathrm{M} 20$ \\
\hline$\theta$ & $\varepsilon_{0}^{\mathrm{pl}}$ & $\varepsilon_{0}^{\mathrm{pl}}$ & $\varepsilon_{0}^{\mathrm{pl}}$ & $\varepsilon_{0}^{\mathrm{pl}}$ \\
\hline 0.15 & 0.304 & 0.046 & 0.039 & 0.029 \\
0.23 & 0.272 & 0.041 & 0.035 & 0.026 \\
0.33 & 0.232 & 0.035 & 0.03 & 0.022 \\
0.67 & 0.139 & 0.021 & 0.018 & 0.013 \\
1 & 0.085 & 0.013 & 0.011 & 0.008 \\
1.33 & 0.052 & 0.008 & 0.007 & 0.005 \\
1.67 & 0.031 & 0.0047 & 0.004 & 0.003 \\
2 & 0.019 & 0.0029 & 0.0024 & 0.0018 \\
\hline
\end{tabular}

Table 4: Shear damage initiation for the 10.9 bolt grade.

\begin{tabular}{cccccc}
\multicolumn{2}{c}{ M16 } & \multicolumn{2}{c}{ M18 } & \multicolumn{2}{c}{ M20 } \\
\hline$\tau_{s}$ & $\bar{\varepsilon}_{s}^{\mathrm{pl}}$ & $\tau_{s}$ & $\bar{\varepsilon}_{s}^{\mathrm{pl}}$ & $\tau_{s}$ & $\bar{\varepsilon}_{s}^{\mathrm{pl}}$ \\
\hline 1.732 & 0.08 & 1.732 & 0.065 & 1.0732 & 0.035 \\
\hline
\end{tabular}

field $\left(\epsilon_{x}\right)$ predicted by FE to those measured using DIC for the M18-5-10 and M18-3-10 specimens, in the plane of the flange thickness. The results correspond to two instances at $\Delta=2 t_{p}($ Figs $10 \mathrm{a}$ 
Table 5: Damage evolution for the S275 steel and 10.9 bolt grade.

\begin{tabular}{cccccccc}
\multicolumn{2}{c}{$\mathrm{S} 275$} & \multicolumn{2}{c}{$\mathrm{M} 16$} & \multicolumn{2}{c}{$\mathrm{M} 18$} & \multicolumn{2}{c}{$\mathrm{M} 20$} \\
\hline$D_{i}$ & $u_{i}^{\mathrm{pl}}$ & $D_{i}$ & $u_{i}^{\mathrm{pl}}$ & $D_{i}$ & $u_{i}^{\mathrm{pl}}$ & $D_{i}$ & $u_{i}^{\mathrm{pl}}$ \\
\hline 0 & 0 & 0 & 0 & 0 & 0 & 0 & 0 \\
0.003 & 0.3 & 0.05 & 1.0 & 0.05 & 0.67 & 0.2 & 1.32 \\
0.034 & 0.403 & 1 & 1.1 & 1.0 & 0.69 & 1.0 & 1.34 \\
0.077 & 0.496 & & & & & & \\
0.140 & 0.623 & & & & & & \\
0.235 & 0.786 & & & & & & \\
0.324 & 0.913 & & & & & & \\
1.0 & 1.427 & & & & & & \\
\hline
\end{tabular}

and 11 ), and at $\mathrm{F}=\mathrm{F}_{\max }$ (Figs $10 \mathrm{p}$ and $11 \mathrm{~b}$ ). $\Delta=2 t_{p}$ was chosen because it corresponds to the start of the second hardening branch. When $\Delta=2 t_{p}$, plastic hinges are visible at both the weld-toe and bolt line. This implies that, up until this point, the flange behaves as predicted by EC3 for Mode 1 failure and $\varepsilon_{x} \approx 0$ between the plastic hinges. With increasing $\Delta$ (i.e. $\Delta>2 t_{p}$ ), the axial tensile strain along the flange increases rapidly due to catenary effects. At $F=F_{\max }$, plastic hinges develop at weld toe in both T-stubs. Note also that the level of axial straining in the flange close to the bolt is higher in the M18-5-10 compared to the M18-3-10 specimen. Specimen M18-5-10 eventually failed by net section collapse as seen in Fig 5 ; whereas, failure is caused by fracture at the weld-toe in the M18-3-10 specimen(see Fig 5d). The differences in the extent of straining at the weld-toe can be attributed to the presence of the heat affected zone this is not modelled by FE.

\section{Analytical model}

Here, an analytical model is developed to introduce $2^{\text {nd }}$ order effects into the tensile response of a T-stub bolted to a rigid support - this is a good approximation of the behaviour of bolted beam-to-column joints where the end-plate is connected to a stiffened column. The aim is not to provide a detailed (nor accurate) prediction of the resistance of a $\mathrm{T}$-stub at ultimate failure; rather, to identify those key geometric and material parameters that controls the development of a 2HB. The mechanical model is identical to the classical T-stub theory, currently in use by EC3 


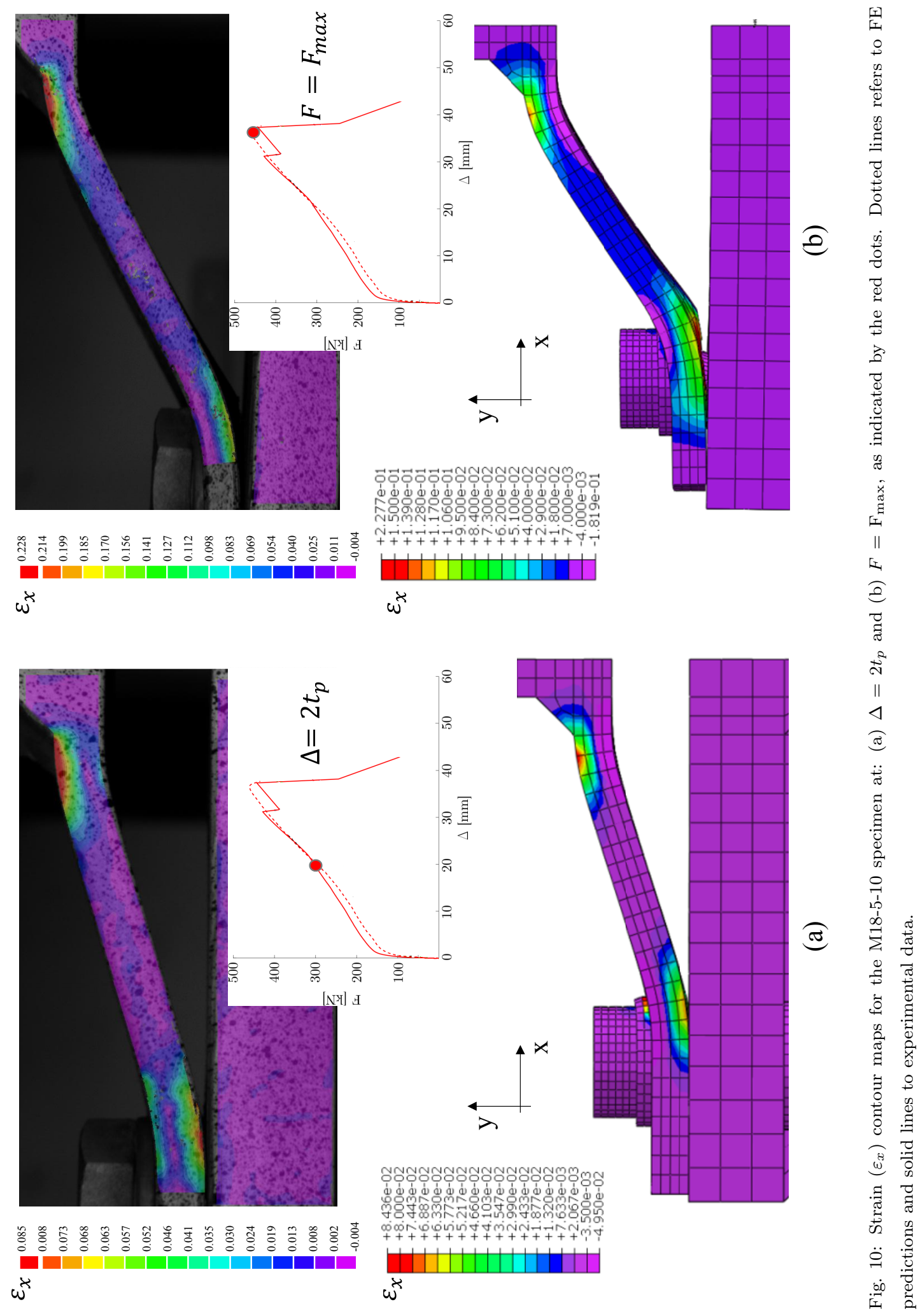




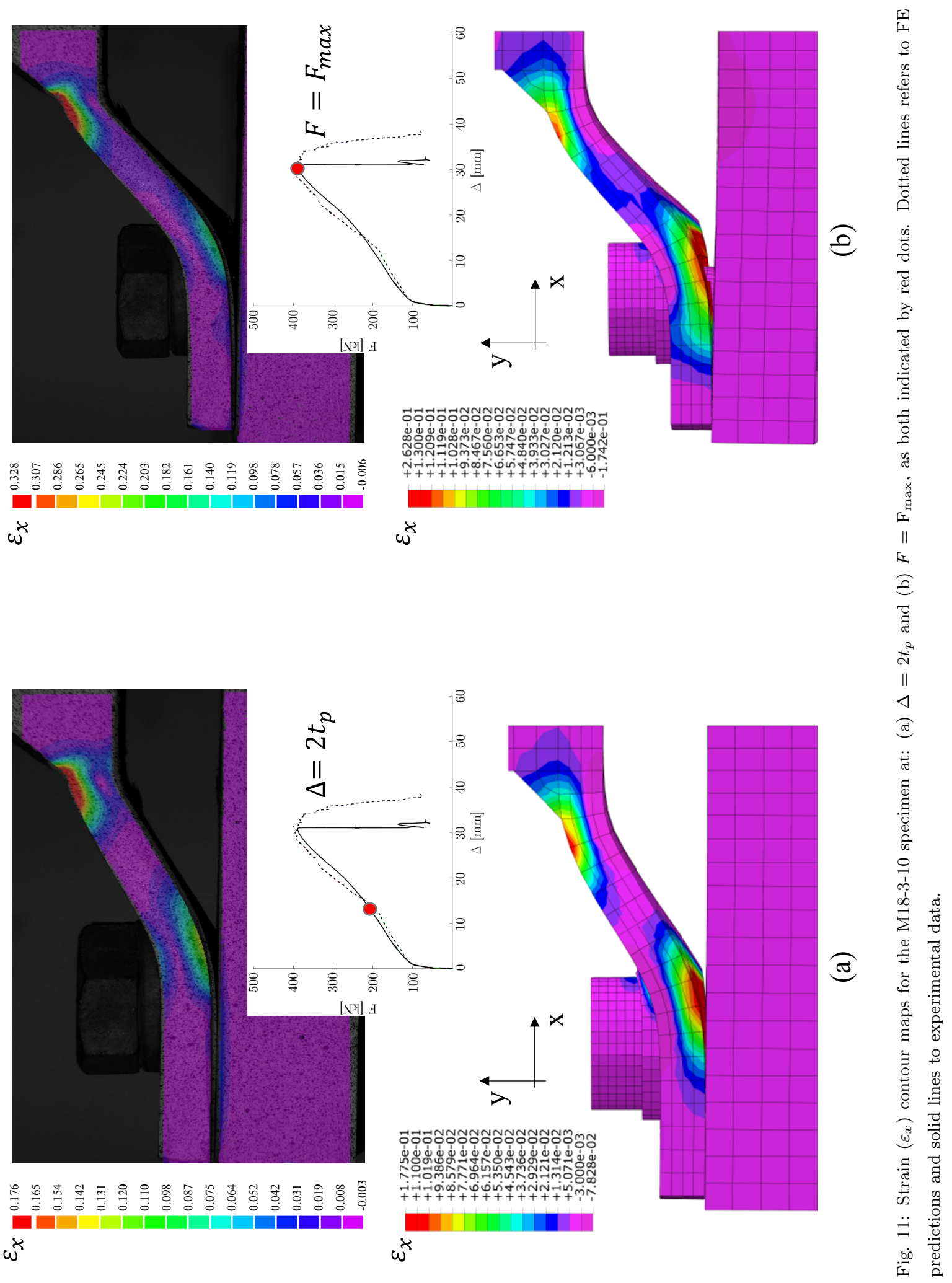


(Part 1.8), but it will be modified to incorporate the contact between the bolt shaft and bolt-hole, this was previously identified to trigger the development of $2^{\text {nd }}$ order effects. A criterion will be proposed to estimate the critical displacement $\left(\Delta_{\text {lim }}\right)$ from where $2^{\text {nd }}$ order effects become active.

\subsection{Formulation}

The model assumes a collapse mechanism typical of a Mode 1 deformation, viz. flange failure through the development of four plastic hinges. A schematic of the kinematic collapse mechanism, and the geometric parameters, is given in Fig 12 . The problem is treated as vertically-symmetric, using a Cartesian $(\mathrm{x}, \mathrm{y})$ coordinate system as shown in Fig 12 a. Note that $n$ and $m$ are defined as in EC3 [7; $\theta$ is the total rotation of the plastic hinges (denoted by black dots in Fig $12 \mathrm{a}$ and b); and, $\Delta$ is the global displacement of the T-stub. Both the flange and bolt are assumed to be made of rigid-perfectly plastic material; hence, $M, B$ and $V$ (see Fig 12 ) are the plastic bending moment of the flange, the plastic tensile strength and plastic shear resistance of the bolt, respectively. In order to obtain a closed form solution, the model ignores the shear-tension interactions in the bolt even though this is likely to be significant. Instead, it will focus on predicting the trend of the $F-\Delta$ response after bolt-hole contact is established so that key geometric and material parameters, controlling the development of $2^{\text {nd }}$ order effects, can be identified.

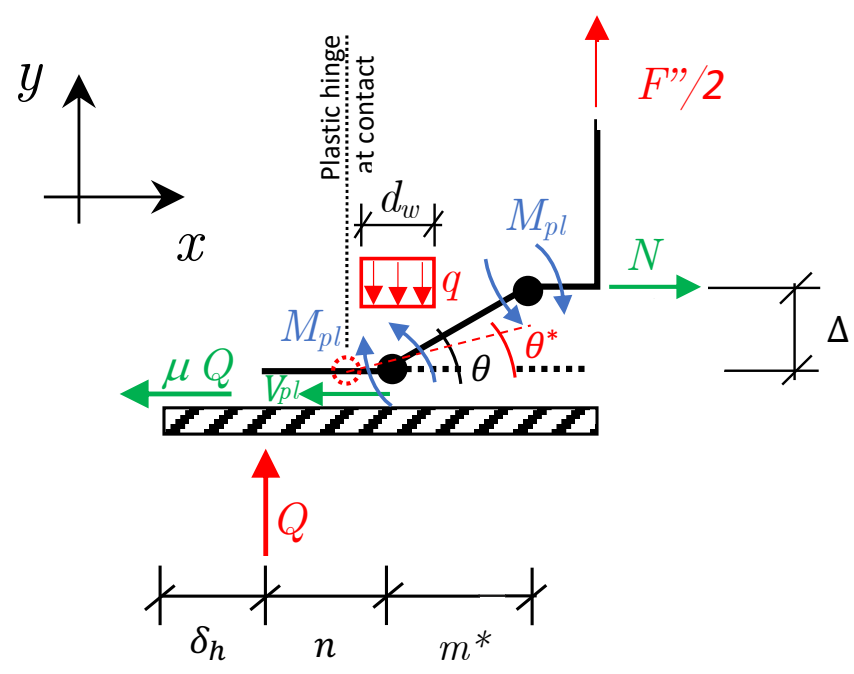

Fig. 12: Plastic collapse mechanism of the T-stub.

Given the mechanism in Fig 12 , the equilibrium equations can be expressed as follows: 


$$
\begin{aligned}
& \frac{F^{\prime \prime}}{2}+Q=q d_{w} \\
& \mu Q+V_{p l}=N \\
& \frac{q d_{w}^{2}}{8}+M_{p l}=Q n \\
& M_{p l}+V_{p l} \Delta+\mu Q \Delta=q d_{w} m^{*}-Q\left(n+m^{*}\right) .
\end{aligned}
$$

Equations $4 \mathrm{a}$ and $4 \mathrm{~b}$ consider vertical and horizontal equilibrium, whereas Eqs $4 \mathrm{c}$ and $4 \mathrm{~d}$ considers the equilibrium of rotation about the bolt axis and the plastic hinge located at the weld, respectively. Note that the resistance of the bolt $\left(q d_{w}\right)$ is treated as a uniformly distributed load along the head of the bolt - this is similar to assumptions made in Method 2 of EC3 [7]. When a T-stub is bolted to a rigid flange, as in this study, the bolt axis is initially positioned along the centreline of the bolt hole, and the hole is pulled towards the bolt by the deformation of the flange and contact is established between bolt and bolt-hole.

From a kinematic perspective, there is no shear force acting in the bolt since the bolt and hole are not initially in contact due to the bolt-hole clearance. Consequently, friction is the only horizontal force and Eqs 4 can be re-written by setting $V_{p l}=0$. Because of compatibility, the vertical displacement $\Delta$ and the T-stub deformation would trigger a horizontal translation of the plate $\delta_{\mathrm{h}}=m(1-\cos \theta)$, see Fig 12 . When $\delta_{h}=\delta_{g}$ (the bolt-hole gap), and assuming a rigid-plastic response of the plate and bolt materials, one may set $V_{p l}=\alpha f_{u b} A_{s}$ (this is the plastic shear resistance of the bolt as described in EC3 [7]) and $N$ becomes equal to $\mu Q+V_{p l}$. Therefore, considering equilibrium of the internal and external virtual work done for the plastic collapse mechanism, in Fig 12 , gives

$$
2 M_{p l} \theta+q \frac{d_{w}^{2}}{8} \tan \theta+\mu Q \delta_{h}+V_{p l} \delta_{b}=\frac{F^{\prime \prime}}{2} \Delta .
$$

The horizontal translation of the bolt $\delta_{b}$ can be expressed as $\delta_{b}=\delta_{h}-\delta_{g}=m\left(\cos \theta^{*}-\cos \theta\right)$, where $\theta^{*}$ is the rotation of the plastic hinge after contact is established between the bolt and hole. The T-stub displacement can be written as $\Delta=m \sin \theta$. Substituting for $\delta_{b}, \Delta$ and $\delta_{h}$ into Eq 5 gives

$$
2 M_{p l} \theta+\frac{q d_{w}^{2}}{8} \tan \theta+\mu Q m(1-\cos \theta)+V_{p l} m\left(\cos \theta^{*}-\cos \theta\right)=\frac{F^{\prime \prime}}{2} m \sin \theta .
$$

Substituting $q d_{w}^{2} / 8$ from $\mathrm{Eq}$ 4 into $\mathrm{Eq} 6$ gives 


$$
\frac{F^{\prime \prime}}{2} m \sin \theta=2 M_{p l} \theta+\mu Q m(1-\cos \theta)+V_{p l} m\left(\cos \theta^{*}-\cos \theta\right)+\frac{F^{\prime \prime}}{16} d_{w} \tan \theta+\frac{Q d_{w}}{8} \tan \theta,
$$

which can be expressed as

$$
F^{\prime \prime}=\frac{4 M_{p l}}{m} f_{1}(\theta)+2 V_{p l} f_{2}(\theta)+2 Q f_{3}(\theta)
$$

where

$$
\begin{aligned}
f_{1}(\theta) & =\frac{\theta}{\sin \theta-\frac{d_{w}}{8 m} \tan \theta} \\
f_{2}(\theta) & =\frac{\cos \theta^{*}-\cos \theta}{\sin \theta-\frac{d_{w}}{8 m} \tan \theta}, \text { for } \theta \geq \theta^{*} \text { and } f_{2}(\theta)=0, \text { for } \theta<\theta^{*} \\
f_{3}(\theta) & =\frac{\mu(1-\cos \theta)+\frac{d_{w}}{8 m} \tan \theta}{\sin \theta-\frac{d_{w}}{8 m} \tan \theta} .
\end{aligned}
$$

An expression for $Q$ can be obtained by extracting $q d_{w}$ from Eq 4 , then substituting this into $\mathrm{Eq} 4 \mathrm{~d}$ to give

$$
M_{p l}+V_{p l} \Delta+\mu Q \Delta=\frac{8 Q n m^{*}}{d_{w}}-\frac{8 M_{p l} m^{*}}{d_{w}}-Q\left(m^{*}+n\right) .
$$

Recall that $\Delta=m \sin \theta$ and $m^{*}=m \cos \theta$, the prying force can now be evaluated as follows:

$$
Q=\frac{M_{p l}\left(8 m \cos \theta+d_{w}\right)+V_{p l} m d_{w} \sin \theta}{8 m \cos \theta n-(m \cos \theta+n) d_{w}-\mu m d_{w} \sin \theta} .
$$

It is worth noting that, if one ignores the influence of both the bolt head $\left(d_{w}=0\right)$ and friction $(\mu=0)$, Eqs 8 and 11 become

$$
Q=\frac{8 M_{p l} m}{8 n m}
$$

and

$$
F^{\prime \prime}=\frac{4 M_{p l}}{m} f_{1}(\theta)+2 V_{p l} f_{2}(\theta)=F^{\prime} f_{1}(\theta)+2 V_{p l} f_{2}(\theta),
$$

where $4 M_{p l} / m=F^{\prime}\left(M_{p l}=b t^{2} / 4 f_{y}[\mathbf{7})\right.$ and

$$
f_{1}(\theta)=\frac{\theta}{\sin \theta},
$$

and

$$
\begin{array}{ll}
f_{2}(\theta)=\frac{\cos \theta^{*}-\cos \theta}{\sin \theta}, & \text { for } \theta \geq \theta^{*} \\
f_{2}(\theta)=0, & \text { for } \theta<\theta^{*},
\end{array}
$$



$\sin \theta \approx \theta, \cos \theta \approx 1), f_{1}(\theta)=0$ and $f_{2}(\theta)=0$; and, Eq 13 simplifies to the one given by EC3 [7], i.e. $F^{\prime \prime}=F^{\prime}$.

Using Eq 13, it is now possible to obtain a closed-form solution to evaluate the critical displacement $\Delta_{\lim }$ beyond which $2^{n d}$ order effects cannot be neglected. Re-arranging Eq 13 , one obtains

$$
k=\frac{F^{\prime \prime}}{F^{\prime}}=f_{1}(\theta)+\frac{V_{p l} m}{2 M_{p l}} f_{2}(\theta)
$$

which is measure of the increased resistance due to the shear in the bolt and the development of geometrical non-linearities. From the above equation, together with a fixed threshold for $k$, it is possible to define the displacement corresponding to the increased resistance. Equation 16 can be simplified by expanding (using Taylor series) $f_{1}(\theta)$ and $f_{2}(\theta)$ to include their $2^{\text {nd }}$ order term. One obtains

$$
f_{1}(\theta)=1
$$

and

$$
f_{2}(\theta)=\frac{\cos \theta^{*}-1}{\theta}+\frac{\theta}{2}
$$

The rotation $\theta^{*}$ can be evaluated as

$$
\theta^{*}=\arccos \left(1-\frac{\delta_{g}}{m}\right)
$$

Substituting Eqs 19 , 17 and 18 into Eq. 16, gives

$$
k-1=-\frac{V_{p l} m}{2 M_{p l}} \frac{\delta_{\mathrm{g}}}{m \theta}+\frac{V_{p l} m}{4 M_{p l}} \theta .
$$

We can now calculate $\theta$ to give

$$
\theta=\frac{2 M_{p l}}{V_{p l} m}(k-1)+\sqrt{\left(\frac{2 M_{p l}(k-1)}{V_{p l} m}\right)^{2}+\frac{2 \delta_{\mathrm{g}}}{m}} .
$$

For $\Delta \cong m \theta$ (this corresponds to evaluating $\Delta$ at $\approx 5 \%$ for $\theta=30^{\circ}$ and $\approx 10 \%$ for $\theta=45^{\circ}$ ), it is possible to derive a simple criterion to calculate the critical displacement $\Delta_{\text {lim }}$ at which $F^{\prime \prime} / F^{\prime}=$ $k$ for a given T-stub dimensions. This critical displacement corresponds to the displacement from where $2^{\text {nd }}$ order effects should not be neglected and is given by

$$
\Delta_{\mathrm{lim}}=\frac{2 M_{p l}(k-1)}{V_{p l}}+\sqrt{\left(\frac{2 M_{p l}(k-1)}{V_{p l}}\right)^{2}+2 \delta_{\mathrm{g}} m} .
$$



deviations occur at very large displacements. This is because the mechanical model neglects the shear-tension interaction in the bolts that provides a final softening branch to failure. In Fig 14 , the difference between the FE and mechanical model is due mainly to material strain-hardening; this difference reduces drastically if the materials are modelled as rigid-perfectly plastic (Fig 13 .

Model prediction of the $\mathrm{F}-\Delta$ response is obtained using Eqs 8,9 and 11 . The results are compared to their FE counterpart in Figs 13 and 14. The former shows the FE predictions if both the flange and bolt were rigid, perfectly-plastic; the latter for the calibrated material model described in Section 2.2. The critical displacement $\Delta_{\lim }$ corresponding to the development of $2^{\text {nd }}$ order effects (in other words, at $F^{\prime \prime} / F^{\prime}=k=1.1$ ) is given by $\mathrm{Eq} 22$ and this is indicated by a solid dot in the corresponding figures. Despite its simplicity, the mechanical model provides a good estimate of the critical displacement $\Delta_{\text {lim }}$ - this is evident in Table 6 . As to be expected, prediction by the mechanical model is somewhat conservative in most cases. From a practical perspective, $\Delta_{\text {lim }}$ identifies the range of validity of the prediction by classical theory where the restraining action of the bolts in shear, originating only at large displacements, is neglected.

The mechanical model is also able to predict the plastic resistance of the T-stubs to a good level of accuracy. The corresponding resistance predicted by EC3 [7] (in red dotted line) is plotted in the same figures for comparison. There is only one case (viz. M18-3-10 in Figs 13b and 14b) where the mechanical model under predicts the plastic resistance. This is due to the combination of thin flange plates and relatively large bolt diameter which renders approximate the measure of the parameter $m$ (defined as the distance between the plastic hinge located at the weld toe and the bolt axis). In some cases, say, for example, M18-3-10, the measure for $m$ is conservative because, in reality, due to the constraining effect provided by the bolt head, the physical position of the plastic hinge at the bolt line shifts from the bolt axis to the bolt head tip (see Fig 11). Overall, the mechanical model provides a satisfactory prediction of the $2 \mathrm{HB}$ (Fig 13 ). However, 


\begin{tabular}{ccc}
\hline Model & $\Delta_{\text {lim }}^{\mathrm{FEM}}$ & $\Delta_{\text {lim }}^{\mathrm{Mech}}$ \\
\hline M16-3-10 & 10.11 & 9.88 \\
M16-5-10 & 13.39 & 14.03 \\
M16-5-15 & 15.01 & 12.98 \\
M18-3-10 & 11.97 & 11.01 \\
M18-5-10 & 12.89 & 12.24 \\
M18-4-15 & 13.23 & 12.06 \\
M18-5-15 & 16.36 & 12.86 \\
M20-3-10 & 12.05 & 11.62 \\
M20-5-10 & 14.86 & 14.25 \\
M20-4-15 & 16.82 & 13.37 \\
M20-5-15 & 16.81 & 17.89 \\
M20-4-20 & 18.58 & 14.70 \\
M20-5-20 & 16.55 & 16.58 \\
\hline
\end{tabular}

Table 6: Critical displacements predicted by FE $\left(\Delta_{\text {lim }}^{\mathrm{FEM}}\right)$ with material strain-hardening and by the simplified rigid, perfectly-plastic mechanical model $\left(\Delta_{\mathrm{lim}}^{\mathrm{Mech}}\right)$. 


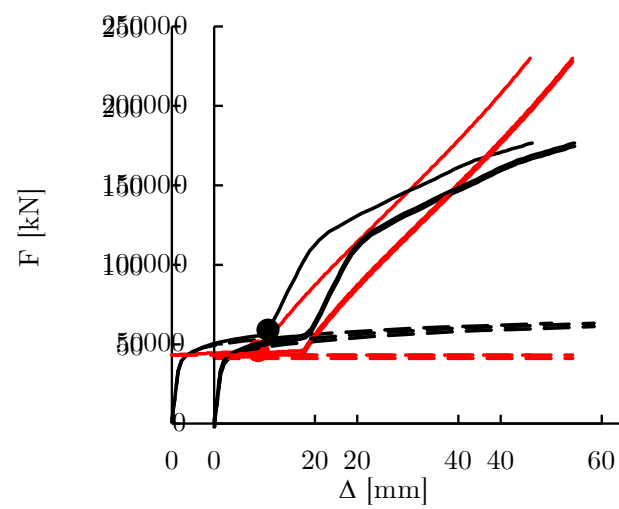

(a) M16-5-10

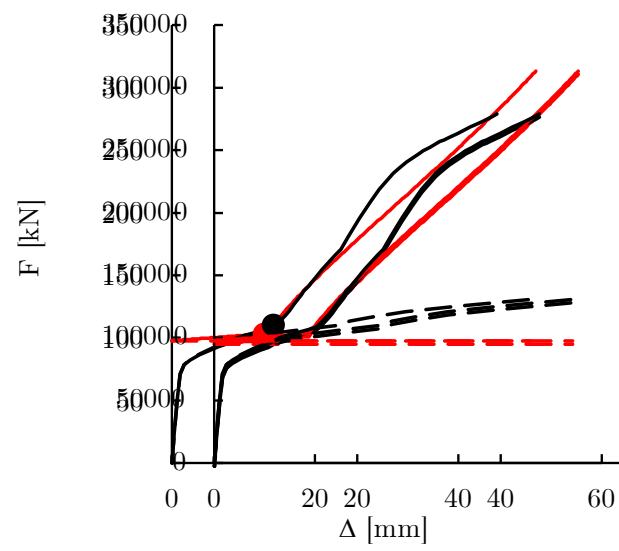

(c) M18-5-15

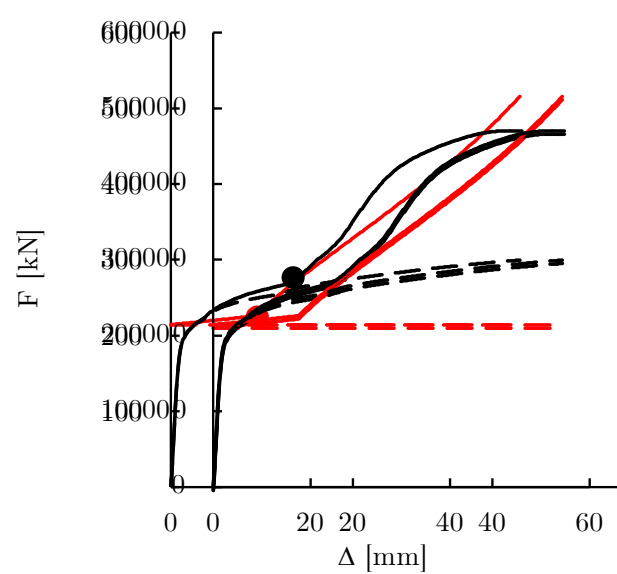

(e) M20-4-20

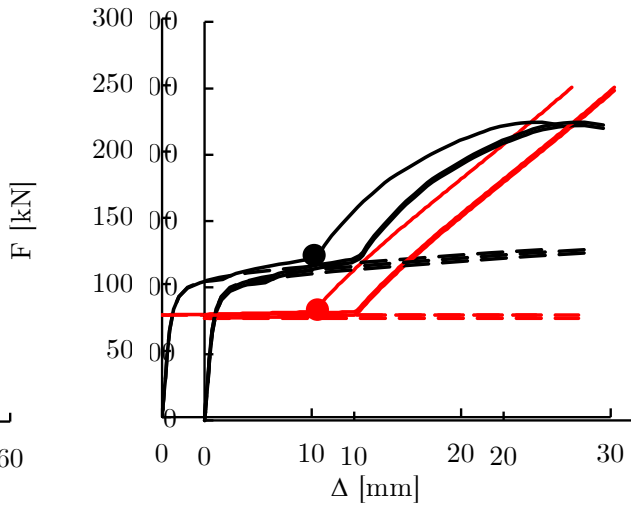

(b) M18-3-10

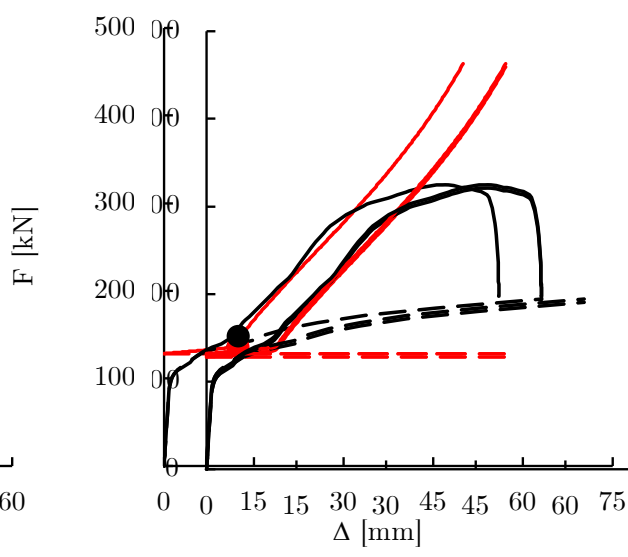

(d) M18-4-15

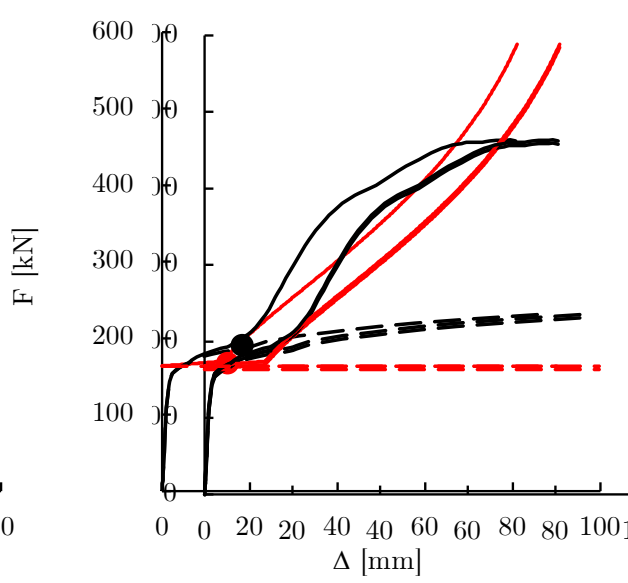

(f) M20-5-20

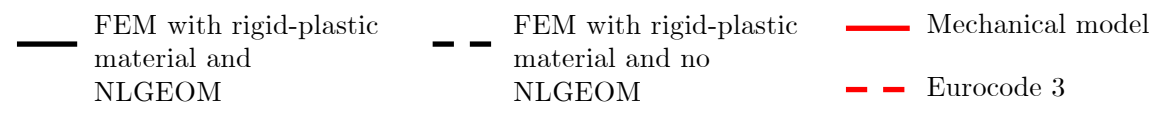

Fig. 13: Predicted F- $\Delta$ response by FE model (assuming rigid, perfectly-plastic flange and bolt materials) and the mechanical model. Black and red dots indicate the critical displacement $\Delta_{\text {lim }}$ predicted by FE and the mechanical model, respectively. 


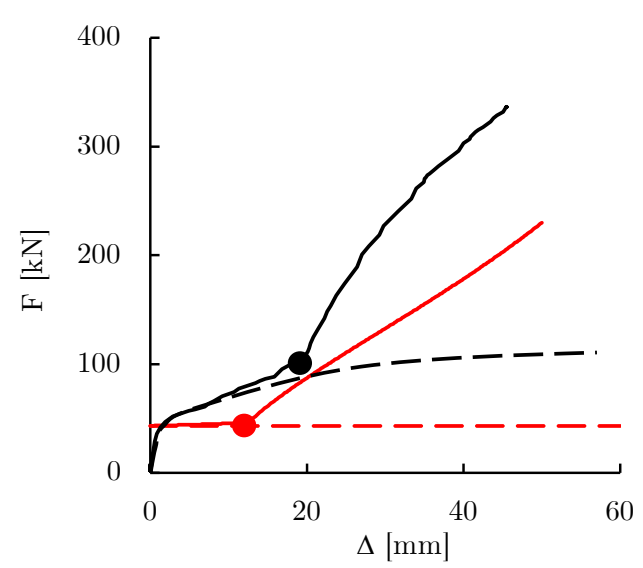

(a) M16-5-10

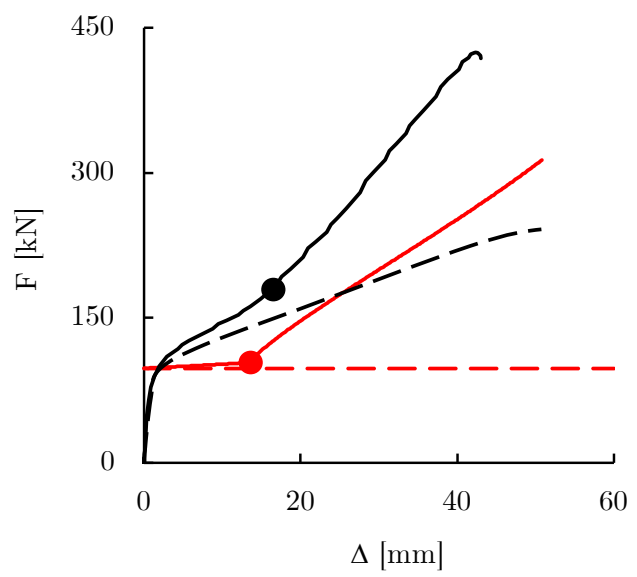

(c) M18-5-15

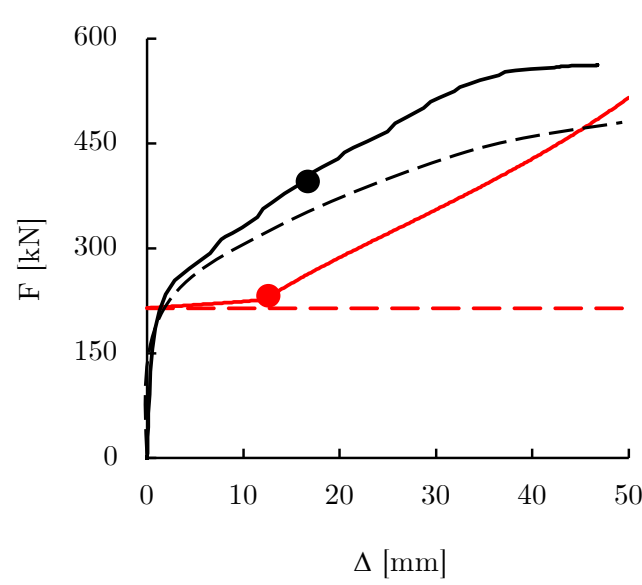

(e) M20-4-20

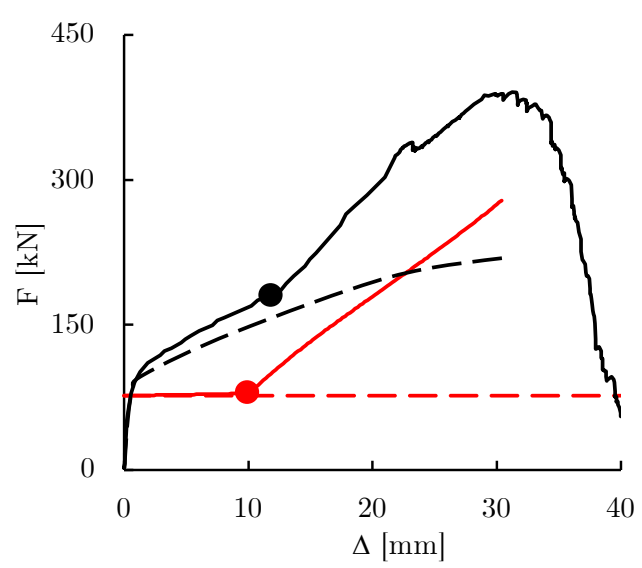

(b) M18-3-10

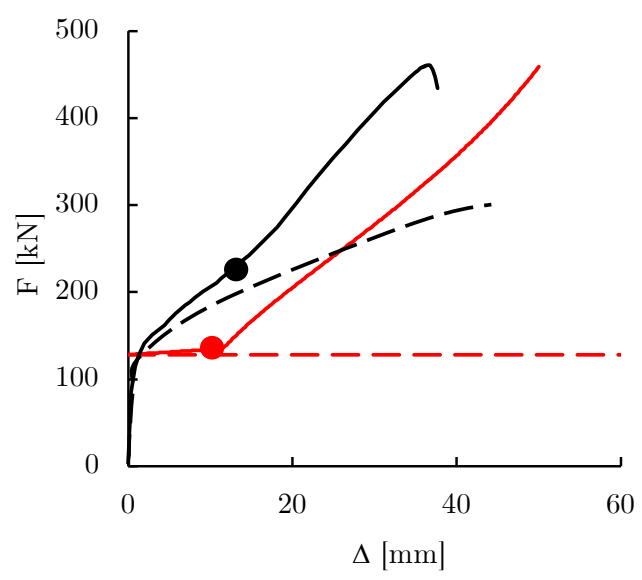

(d) M18-4-15

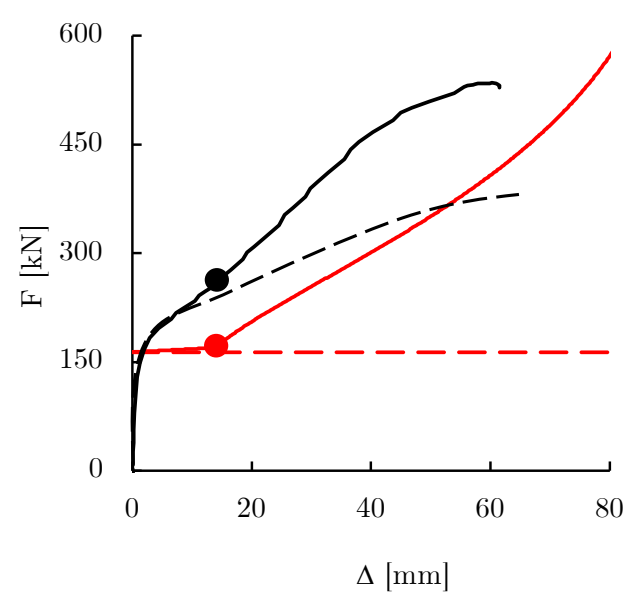

(f) M20-5-20
FEM with elasticplastic material and NLGEOM

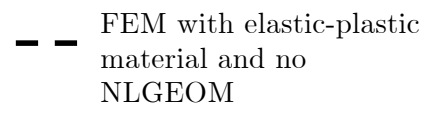
material and no NLGEOM

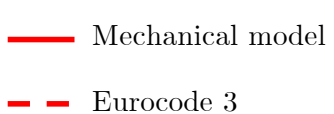

- - Eurocode 3

Fig. 14: Predicted F- $\Delta$ response by FE model (using calibrated material properties described in Section 2.2 and the mechanical model. Black and red dots indicate the critical displacement $\Delta_{\text {lim }}$ predicted by FE and the mechanical model, respectively. 


\section{Conclusions}

The constraining effect provided by the bolt in shear was shown to trigger the development of axial forces in the flange plate, giving rise to failure modes that are not previously captured by classical theory, or by FE models that neglect geometric nonlinearity. Through a combined experimental and numerical approach, two further modes of failure (bolt failure under combined tensile, shear forces and bending moment; necking at the bolt-hole) were identified in this work. Finite element models (incorporating both tensile and shear damage in the flange and bolts) were created and they were shown to predict well the key parameters (stiffness, ductility, plastic and ultimate strength) of a T-stub response. A mechanical model was also developed that successfully identifies the key geometric and material parameters governing the transition to a second hardening branch. The corresponding critical displacement was derived and its prediction, although conservative, was shown to be reasonably accurate.

\section{Acknowledgements}

The authors at University College London are grateful to the Ministry of Defence, UK (David Manley - DE\&S Sea Systems Group) and QinetiQ (Robert Ball - Structures \& Survivability, Platform Design and Life Support IDT) for financial support.

\section{References}

[1] Y.C. Wang, X.H. Dai, C.G. Bailey. An experimental study of relative structural fire behaviour and robustness of different types of steel joint in restrained steel frames. Journal of Constructional Steel Research, 67:1149-1163, 2011.

[2] V. Rodrigues Gomes, A. Tenchini, L. Lima, P. Vellasco. Robustness assessment of semi-rigid steel multi-storey frames. Structures, 25:849-860, 2020.

[3] B. Ghorbanzadeh, G. Bregoli, G. Vasdravellis, T.L. Karavasilis. Pilot experimental and numerical studies on a novel retrofit scheme for steel joints against progressive collapse. Engineering Structures, 200, 2019.

[4] F. Santos, A. Santiago, M. Latour, G. Rizzando. Robustness analysis of steel frames subjected to vehicle collisions. Structures, 25:930-942, 2020. 
[5] R. Zandonini, N. Baldassino, G. Freddi, F. amd Roverso. Steel-concrete frames under the column loss scenario: An experimental study. Journal of Constructional Steel Research, 162, 2019.

[6] C.A. Dimopoulos, F. Freddi, T.L. Karavasilis, G. Vasdravellis. Progressive collapse resistance of steel self-centering mrfs including the effects of the composite floor. Engineering Structures, 208, 2020.

[7] CEN. Eurocode 3: Design of steel structures - Part 1-8: Design of joints. CEN, Brussel: European Commitee for Standardization, 2005.

[8] A.M. Girão Coelho. Rotation capacity of partial strength steel joints with three-dimensional finite element approach. Comput. Struct., 116:88-97, 2013.

[9] R. Tartaglia, M. D’Aniello, G.A. Rassati, J.A. Swanson, R. Landolfo. Full strength extended stiffened end-plate joints: Aisc vs recent european design criteria. Engineering Structures, 159, 2018.

[10] R. Tartaglia, M. D'Aniello, M. Zimbru, R. Landolfo. Finite element simulations on the ultimate response of extended stiffened end-plate joints. Steel and Composite Structures, An International Journal, 27:727-745, 2018.

[11] R. Tartaglia, M. D'Aniello, R. Landolfo. The influence of rib stiffeners on the response of extended end-plate joints. Journal of Constructional Steel Research, 2018.

[12] A.M. Girão Coelho, F.S.K. Bijlaard, N. Gresnigt, L. Simões da Silva. Experimental assessment of the behaviour of bolted T-stub connections made up of welded plates. J. Constr. Steel Res., 60(2):269-311, 2004. doi: 10.1016/j.jcsr.2003.08.008.

[13] A.M. Girão Coelho, F.S.K. Bijlaard, L. Simões da Silva. Experimental assessment of the ductility of extended end plate connections. Engineering Structures, 26(9):1185-1206, 2004.

[14] M. Latour, G. Rizzano, A. Santiago, D. Simoes. Experimental analysis and mechanical modeling of t-stubs with four bolts per row. Journal of Constructional Steel Research, 101: 158-174, 2014.

[15] R. Tartaglia, M. D’Aniello, A. De Martino. Ultimate performance of external end-plate bolted joints under column loss scenario accounting for the influence of the transverse beam. The Open Construction and Building Technology Journal, 12:132-139, 2018. 
[16] R. Tartaglia, M. D'Aniello. A nonlinear performance of extended stiffened end plate bolted beam-to-column joints subjected to column removal. The Open Civil Engineering Journal, 11:369-383, 2017.

[17] J. Ribeiro, A. Santiago, C. Riguerio, P. Barata, M. Veljkovic. Numerical assessment of t-stub component subjected to impact loading. Engineering Structures, 106:450-460, 2016.

[18] J. Ribeiro, A. Santiago, C. Rigueiro, L. Simões da Silva. Analytical model for the response of T-stub joint component under impact loading. J. Constr. Steel Res., 106:23-34, 2015.

[19] P. Barata, J. Ribeiro, C. Riguerio, A. Santiago, J.P. Rodrigues. Assessment of the t-stub joint component at ambient and elevated temperatures. Fire Safety Journal, 70:1-13, 2014.

[20] V. Piluso, C. Faella, G. Rizzano. Ultimate behavior of bolted T-stubs. II: Model validation. J. Struct. Eng., 127:694-704, 2001.

[21] V. Piluso, C. Faella, G. Rizzano. Ultimate behavior of bolted T-stubs. I: Theoretical model. J. Struct. Eng., 127:686-693, 2001.

[22] M. Liu, X. Zhu, P. Wang, W. Tuoya, S. Hu. Tension strength and design method for thread-fixed one-side bolted t-stub. Engineering Structures, 150:918-933, 2017.

[23] Y. Zhang, M. Liu, Q. Ma, Z. Liu, P. Wang, C. Ma, L. Sun. Yield line patterns of t-stubs connected by thread-fixed one-side bolts under tension. Journal of Constructional Steel Research, 166, 2020.

[24] A.M. Girão Coelho. Characterization of the ductility of bolted end plate beam-to-column steel connections. PhD thesis, Universidade de Coimbra, 2004.

[25] A.M. Girão Coelho, L. Simões da Silva, F.S.K. Bijlaard. Experimental assessment of the ductility of extended end plate connections. Journal of Structural Engineering, 132(6): 918-928, 2006.

[26] A.M. Girão Coelho, F.S.K. Bijlaard. Experimental behaviour of high strength steel end-plate connections. Journal of Constructional Steel Research, 63(9):1228-1240, 2007.

[27] F. Dinu, D. Dubina, I. Marginean, C. Neagu, I. Petran. Axial strength and deformation demands for T-stub connection components at catenary stage in the beams. In 8th Int. Conf. Behav. Steel Struct. Seism. Areas, 2015. 
[28] M. Latour, G. Rizzano. Experimental Behavior and Mechanical Modeling of Dissipative T-Stub Connections. J. Struct. Eng., 138(2):170-182, 2012.

[29] M.S. Zhao, C.K. Lee, S.P. Chiew. Tensile behavior of high performance structural steel T-stub joints. J. Constr. Steel Res., 122:316-325, 2016.

[30] A.C. Faralli, M. Latour, PJ. Tan, G. Rizzano. Finite Element Analysis of Bolted T-Stubs Undergoing Large Displacement : Finite Element Analysis of Bolted T-Stubs Undergoing Large Displacement: A Preliminary Study. Open Constr. Build. Technol. J., 12:170-176, 2018.

[31] A.C Faralli, M. Latour, P.J. Tan, G. Rizzano. On the large deformation of bolted t-stubs. Manuscript submitted to Journal of Constructional Steel Research, 2020. 